\title{
The influence of DC stray current on pipeline corrosion
}

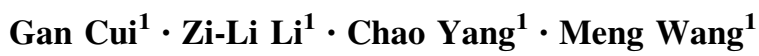

Received: 4 February 2015/Published online: 25 November 2015

(c) The Author(s) 2015. This article is published with open access at Springerlink.com

\begin{abstract}
DC stray current can cause severe corrosion on buried pipelines. In this study, firstly, we deduced the equation of DC stray current interference on pipelines. Next, the cathode boundary condition was discretized with pipe elements, and corresponding experiments were designed to validate the mathematical model. Finally, the numerical simulation program BEASY was used to study the corrosion effect of DC stray current that an auxiliary anode bed generated in an impressed current cathodic protection system. The effects of crossing angle, crossing distance, distance of the two pipelines, anode output current, depth, and soil resistivity were investigated. Our results indicate that pipeline crossing substantially affects the corrosion potential of both protected and unprotected pipelines. Pipeline crossing angles, crossing distances, and anode depths, our results suggest, have no significant influence. Decreasing anode output current or soil resistivity reduces pipeline corrosion gradually. A reduction of corrosion also occurs when the distance between two parallel pipelines increases.
\end{abstract}

Keywords DC stray current $\cdot$ BEASY $\cdot$ Numerical simulation $\cdot$ DC interference corrosion

$\mathrm{Zi}-\mathrm{Li} \mathrm{Li}$

cygcx@163.com

Gan Cui

chennacuigan@163.com

1 College of Pipeline and Civil Engineering, China University of Petroleum (East China), Qingdao 266580, Shandong, China

Edited by Yan-Hua Sun

\section{Introduction}

Stray current refers to the current that flows elsewhere rather than along the intended current path. It is an important cause of corrosion and leakage of underground metal pipelines ( $\mathrm{Li}$ et al. 2010; Guo et al. 2015). Stray current corrosion is essentially electrochemical corrosion (Bertolini et al. 2007). Because of the high electrical conductivity of buried steel pipelines, potential differences with the less conductive environment are formed when stray current flows through the pipe (Brichau et al. 1996) effectively creating a corrosion cell. The corrosion caused by stray current is more serious than soil corrosion under normal conditions (the potential difference of soil corrosion is only about $0.35 \mathrm{~V}$ without stray current, but the pipe-to-soil potential can be as high as $8-9 \mathrm{~V}$ when a stray current exists) (Brichau et al. 1996). The stray current has a great effect on corrosion, and so affects the service life and safe use of buried pipelines (Ding et al. 2010). Therefore, it is important to better understand stray current corrosion.

There are three types of stray currents: direction current (DC), alternating current (AC), and natural telluric current in the earth. Among these, the DC stray current causes most damage to a buried pipeline (Gao et al. 2010). The DC stray current mainly originates from DC electrified railways, DC electrolytic equipment grounding electrodes, and the anode bed of cathodic protection systems (Wang et al. 2010).

Numerical methods have been shown to be powerful tools to analyze corrosion problems in the last two decades. Numerical methods used for corrosion studies include the finite difference method (FDM), the finite element method (FEM) (Xu and Cheng 2013), and the boundary element method (BEM) (Metwally et al. 2007; Boumaiza and Aour 2014; Bordón et al. 2014). The BEM was applied to model 
cathodic protection systems in the early 1980s (Wrobel and Miltiadou 2004; DeGiorgi and Wimmer 2005; Lacerda et al. 2007; Abootalebi et al. 2010; Lan et al. 2012; Liu et al. 2013). Compared with FDM and FEM, BEM requires the meshing of the boundary only. As a result, BEM needs fewer equations resulting in a smaller matrix size than FEM and can solve both finite and infinite domain problems (Jia et al. 2004; Parvanova et al. 2014). Last but not least, the BEM has been specifically developed to calculate the DC stray current induced in pipeline networks by electric railways and can model the soil and the entire traction system consisting of rails, traction stations, overhead wires, and trains (Bortels et al. 2007; Poljak et al. 2010)

In this paper, the BEM is carried out to determine the effect of DC interference corrosion on neighboring pipelines (crossing or parallel with the cathodic protection pipeline). It focuses on the DC current produced by the auxiliary anode of the impressed current cathodic protection system.

\section{Mathematical model}

\subsection{Governing equation}

Some simplifications and assumptions are made here: the solution around the pipeline is uniform and electroneutral, and there is no concentration gradient in the solution.

Based on the above assumption and Ohm's law, the current density $i$ can be expressed as follows (Metwally et al. 2008):

$i=\sigma_{\mathrm{e}} e$,

where $\sigma_{\mathrm{e}}$ is the electrical conductivity of soil in $\mathrm{S} / \mathrm{m} ; i$ is the current density in $\mathrm{mA} / \mathrm{m}^{2}$; and $e$ is the electric field in $\mathrm{V} / \mathrm{m}$. Then, the static form of the equation of continuity can be given as

$\nabla i=\nabla\left(\sigma_{\mathrm{e}} e\right)=0$.

Under static conditions, the electric potential is defined by the following equivalent equation:

$\nabla \phi=e$.

Consequently, the governing equation for the electric potential is the Laplace equation (Thamita 2012):

$\Delta \phi=0$.

\subsection{Boundary conditions}

Boundary conditions can be divided into the anode boundary condition, the cathode boundary condition, and the insulation boundary condition.

\subsubsection{Anode and insulation boundary conditions}

In this simulation, an impressed current cathodic protection system is used and it is assumed that the output current of the auxiliary anode is constant. Thus, the anode boundary condition can be described as (Lan et al. 2012)

$I=I_{0}$.

The insulation boundary condition can be described as $\frac{\partial \phi}{\partial n}=0$.

\subsubsection{Cathode boundary condition}

On the surface of the cathode, many complex electrochemical reactions occur. Polarization is one such consequence of these reactions. The polarization data will be used as the cathode boundary.

The polarization curve of steel was measured in the soil environment using a conventional three-electrode cell assembly. Rectangular platinum shapes were used as the counter electrode and a saturated copper sulfate electrode as reference. The working electrode was a cuboid, and its material was Q235 steel. The steel electrode was embedded in epoxy resin so that only a $1-\mathrm{cm}^{2}$ area of the cuboid was exposed to the soil. Before the experiment, the working electrode was polished gradually using 600-1200 grid, waterproof abrasive paper. It was then washed with distilled water, degreased with acetone, and washed with ethanol. Finally, it was dried in an unheated air stream. Electrochemical measurements were carried out using electrochemical workstation Parstat 2273, which was specially designed for the study of the electrochemical corrosion behavior. It can be used to test the open circuit potential, electrochemical impedance spectroscopy (EIS), Tafel polarization curve, cyclic voltammograms, etc. In this paper, the Tafel curve was tested, and the polarization measurement involved a scan starting from -400 to $-1200 \mathrm{mV}$ at a scan rate of $0.3 \mathrm{mV} / \mathrm{s}$.

The polarization curve is used as the cathode boundary condition, but it is a nonlinear curve, so we have to use polarization data in a piecewise linear interpolation approach (Abootalebi et al. 2010; Liang et al. 2011; Liu et al. 2013; Li et al. 2013). The polarization curve is shown in Fig. 1, and we present it as a piecewise linear curve.

\subsection{Boundary element method (BEM)}

When the BEM is applied, only the boundaries of the domain need to be discretized. The pipeline is discretized using the pipe element method, see Fig. 2. The number of nodes and elements is reduced a lot with this method and as a result the computation is simplified. 

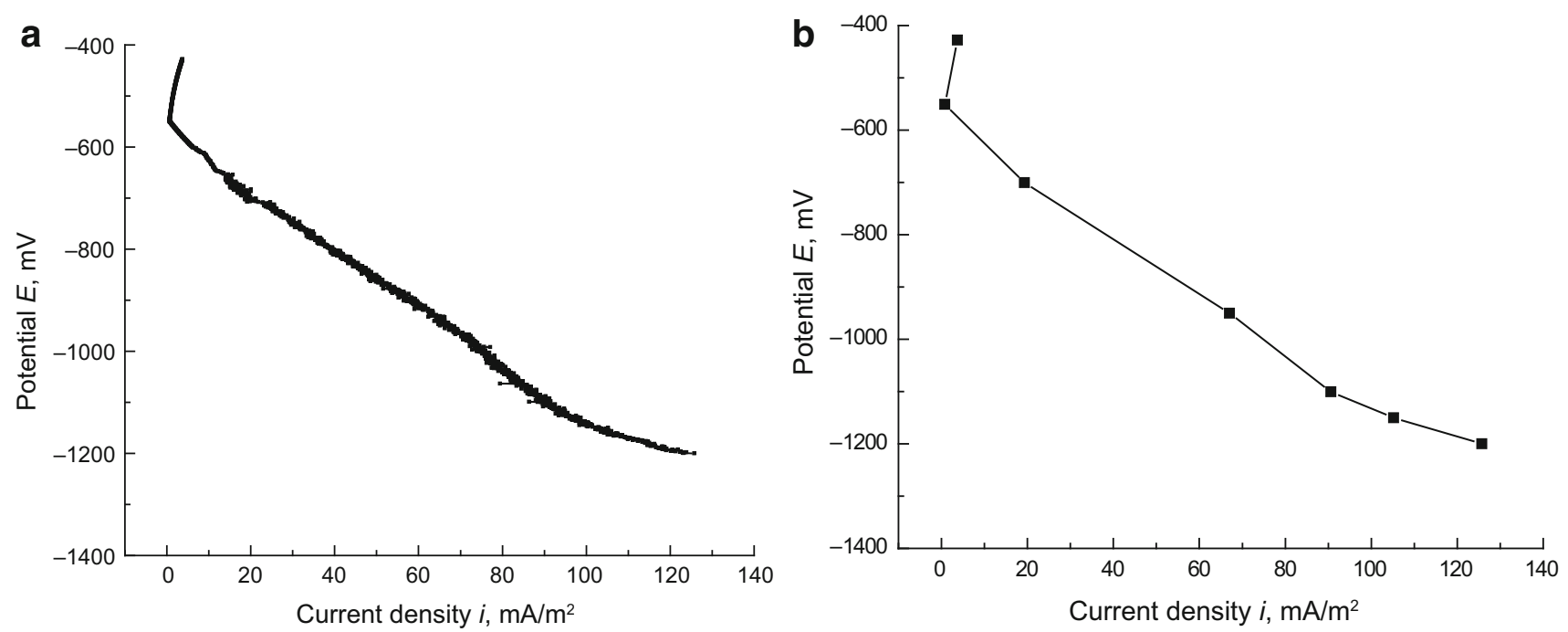

Fig. 1 The polarization curve. a Experimental polarization curve. b Piecewise linear polarization curve

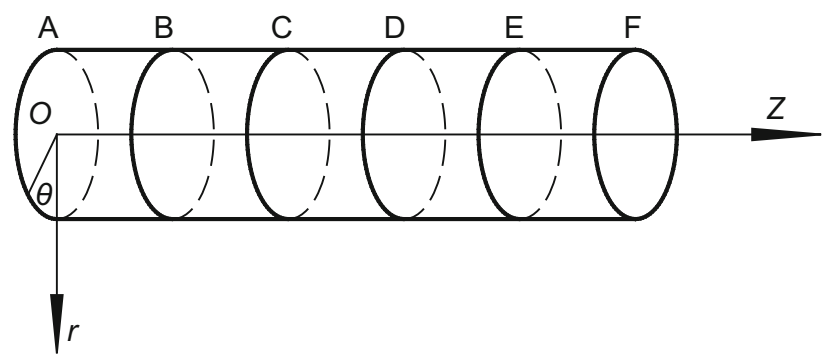

Fig. 2 Pipe surface discretization

It should be noted that certain conditions need to be met to use the pipe element method (Meng et al. 1998). (1) The geometry of the protected body needs to be suitable for cylinder unit subdivision. (2) The potential everywhere on the same cylinder unit is considered constant.

It is known that the fundamental solution of the boundary integral equation is $\frac{1}{4 \pi r}$. Here " $r$ " refers to the distance between the boundary node and the source node. Therefore, the integration will become a singularity when the boundary node coincides with the source node.

\subsubsection{Computation of the nonsingular coefficient}

Based on the pipe element method above together with the standard BEM formula, to make the boundaries discrete, the coefficient matrix of each element is obtained by integral transformation (Brichau and Deconinck 1994).

$G_{i, j m}(t)=4 \frac{R L}{4 \pi}|J| \phi_{m}(t) \frac{4 K(k)}{\left[(R+B)^{2}+\left(L t-Z_{r n}\right)^{2}\right]^{1 / 2}}$,

$$
\begin{aligned}
& H_{i, j m}(t)=|J| \phi_{m}(t) \\
& \quad \frac{-R L}{\left[(R+B)^{2}+\left(L t-Z_{r n}\right)^{2}\right]^{1 / 2}} \frac{\left(L t-Z_{r n}\right) E(k)}{\pi\left[(R-B)^{2}+\left(L t-Z_{r n}\right)^{2}\right]^{2}} .
\end{aligned}
$$

In Eqs. (7) and (8), $i \neq j . K(k)$ is the elliptic integral of the first kind, while $E(k)$ is the elliptic integral of the second kind; $J$ and $B$ are the results of the coordinate transformation; $t$ is the local coordinate; and $Z_{r n}$ is the third coordinate of the last pipe element node.

\subsubsection{Computation of the singular coefficient}

For the semi-infinite region (Wu 2008),

$H_{i i}=-\sum H_{i j}, \quad i \neq j$.

The analytical method to solve $G_{i i}$ is

$G_{i i}=\frac{L}{2 \pi}\left[1-\ln \left(\frac{L}{16 r}\right)\right]$.

Finally, the standard BEM formula is represented by a numerical integral, with the result

$\{G\} \times\{Q\}=\{H\} \times\{\phi-\eta(Q)\}$.

\section{Experimental}

To validate the mathematical model, related experiments were carried out in a controlled laboratory environment.

\subsection{Experimental design}

An experimental box was made of wood, $8000 \mathrm{~mm} \times$ $6000 \mathrm{~mm} \times 1500 \mathrm{~mm}$ (length $\times$ width $\times$ height), covered 
with an insulating board. We also placed a PVC board under it and around it. Two steel pipes were buried inside the box: the protected pipe and the DC-interfered pipe. The parameters of the protected pipe were material Q235 steel-no coating, outside diameter $20 \mathrm{~mm}$, wall thickness $3 \mathrm{~mm}$, length $6000 \mathrm{~mm}$, and depth $1 \mathrm{~m}$. The parameters of the DCinterfered pipe were material Q235-no coating, outside diameter $20 \mathrm{~mm}$, wall thickness $3 \mathrm{~mm}$, length $4000 \mathrm{~mm}$, depth $0.5 \mathrm{~m}$. The parameters of the auxiliary anode with a treated cylindrical surface were diameter $0.03 \mathrm{~m}$, length $0.1 \mathrm{~m}$, depth $1 \mathrm{~m}$, distance from the pipe $0.3 \mathrm{~m}$, no fillers, and the output current $1 \mathrm{~mA}$.

The test points were set up on the pipes as shown in Fig. 3. Three cables of potentiostat (DJS-292) were connected to the energized point of the pipe, the auxiliary anode, and the reference electrode, respectively. The reference electrode was a saturated copper-copper sulfate electrode (CSE), which was buried near the energized point.

The cathodic protection potential data were acquired with an NIUSB6210 data acquisition module using a test block power interruption method.

\subsection{Comparison between simulation and experimental results}

Figure 4 shows the measured and simulated potentials at test points on the protected pipe. Experimental results for the DC-interfered pipe are shown in Fig. 5.

Figures 4 and 5 show that the experimental data are in relatively good agreement with simulation results. The biggest difference is less than $15 \mathrm{mV}$ which is less than $2 \%$. So the mathematical model of the DC stray current interference is fairly accurate. BEM modeling proves to be very effective for simulating DC stray current interference on pipelines.

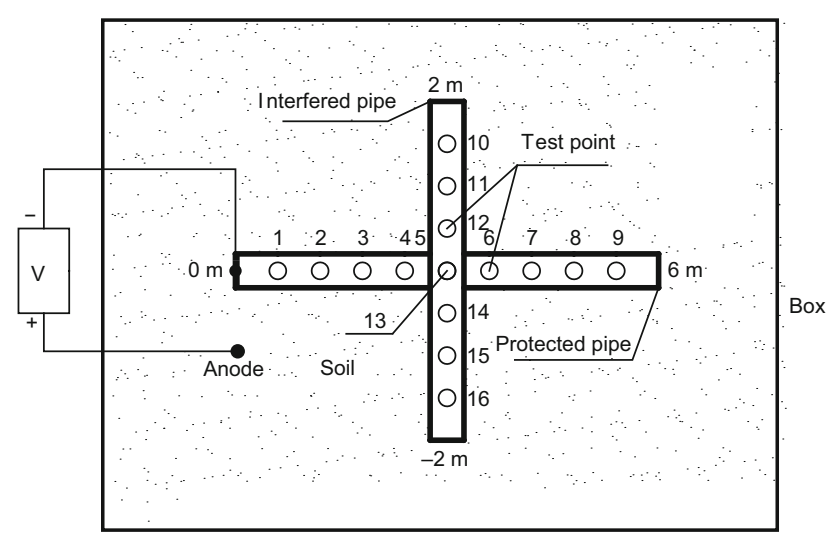

Fig. 3 Schematic diagram of the experimental setup

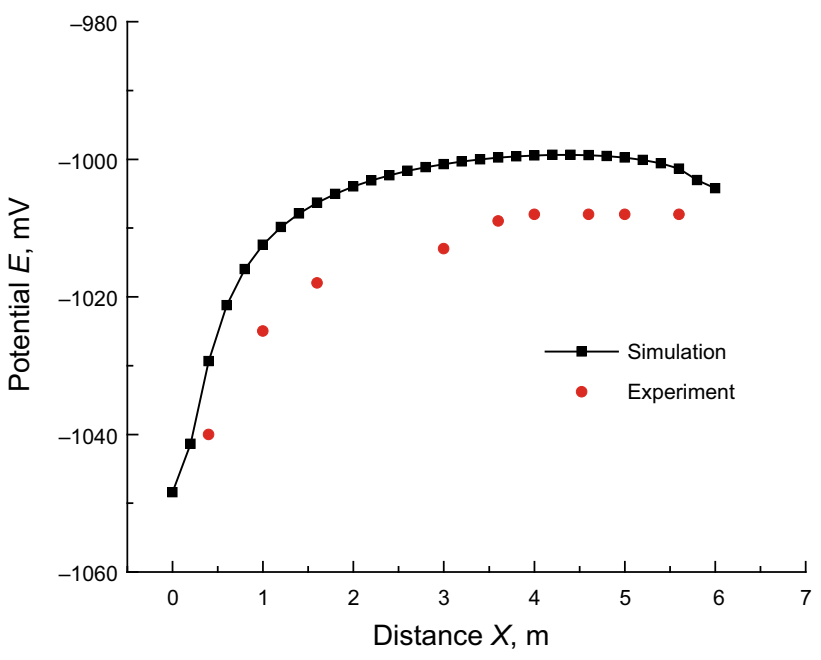

Fig. 4 Potentials on the protected pipe

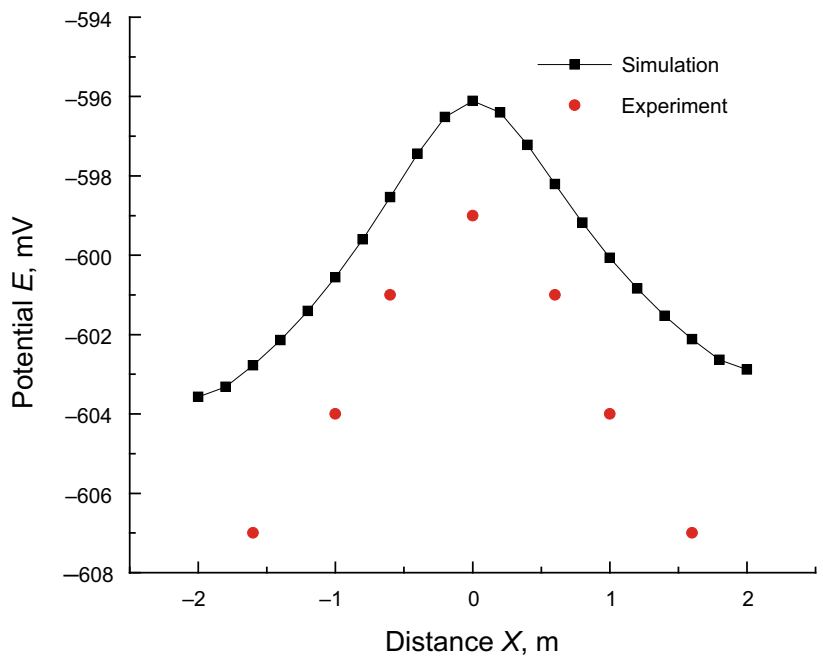

Fig. 5 Potentials on the DC-interfered pipe

\section{Simulation with BEASY}

In this paper, the boundary element numerical simulation software BEASY was used. The simulation model was performed in accordance with Fig. 6. For BEM simulations, the structures under study have been located inside a big cubic box. According to BEASY recommendations (BEASY 2005), the simulation box has to be 20 times the size of the model. The box surrounding the model does not need so many elements unless the model is placed very close to it. As long as the model is very far from the box walls, the current should not reach the box. Therefore, there is no need to put so many elements; 4 elements/face of the box (including the ground) would be fine ( $\mathrm{Wu}$ et al. 2011).

The model includes the following: an impressed current cathodic protection system (ICCP) with a protected 


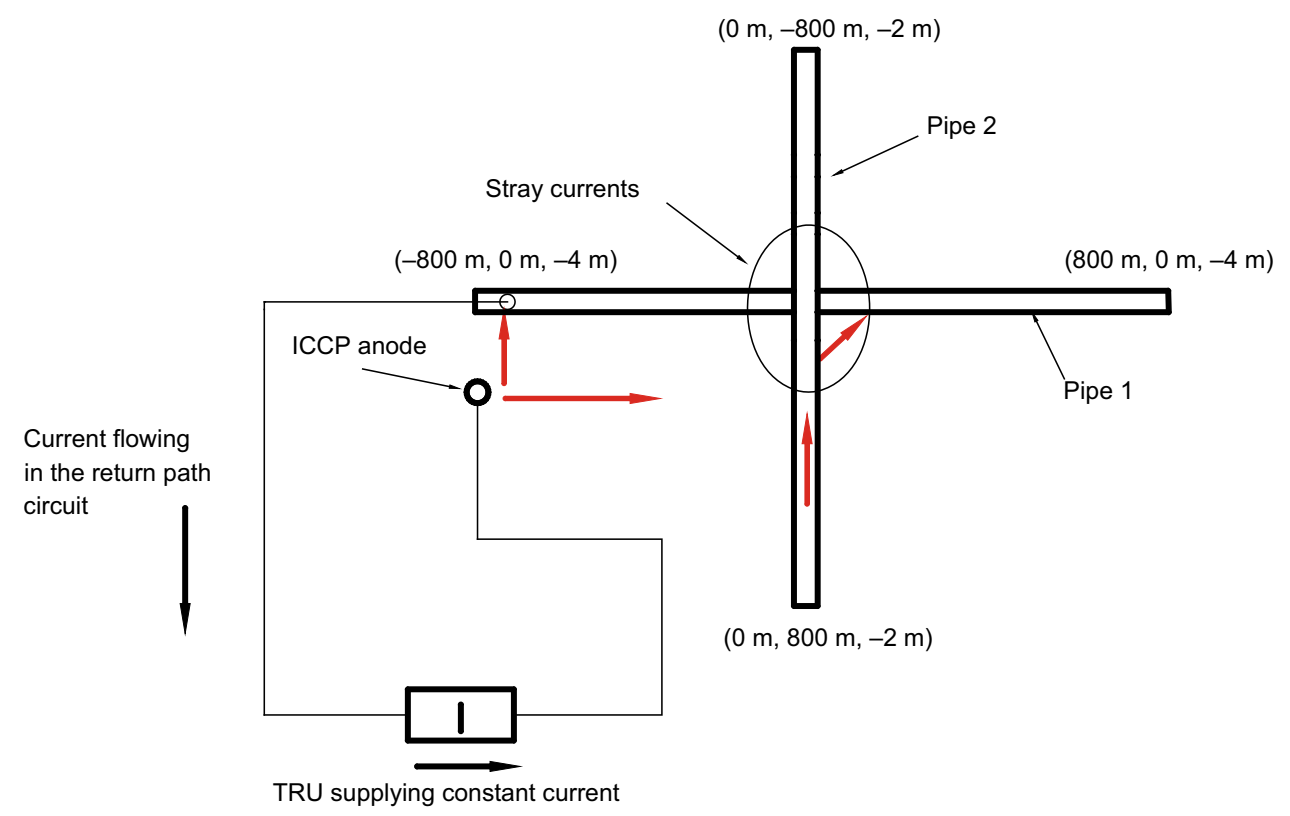

Fig. 6 Schematic of the DC interference model. The anode ground bed produces the DC stray current. Pipeline 2 is rotated anticlockwise to study four different crossing angles $\left(30^{\circ}, 45^{\circ}, 60^{\circ}\right.$, and $\left.90^{\circ}\right)$

pipeline (pipeline 1). Pipeline 2 is located near pipeline 1 and has no applied cathodic protection. Therefore, part of the cathodic protection current that the auxiliary anode carries to pipeline 1 will flow into pipeline 2 as stray current and affects the corrosion of pipeline 2-see Fig. 6.

The origin is chosen as the intersection between the two pipelines, and the parameters in the model are set as follows: Pipeline 1: Two endpoint coordinates are $(-800 \mathrm{~m}, 0 \mathrm{~m}$, $-4 \mathrm{~m})$ and $(800 \mathrm{~m}, 0 \mathrm{~m},-4 \mathrm{~m})$, diameter is $0.762 \mathrm{~m}$, and the material is Q235; Pipeline 2: Two endpoints coordinate are $(0 \mathrm{~m},-800 \mathrm{~m},-2 \mathrm{~m})$ and $(0 \mathrm{~m}, 800 \mathrm{~m},-2 \mathrm{~m})$, diameter is $0.4064 \mathrm{~m}$, and the material is Q235. The coating on both pipelines is assumed to have $5 \%$ damage. The auxiliary anode which is vertically buried has the following parameters: two endpoint coordinates $(-800 \mathrm{~m},-100 \mathrm{~m},-1 \mathrm{~m})$ and $(-800 \mathrm{~m},-100 \mathrm{~m},-6 \mathrm{~m})$, diameter $0.1 \mathrm{~m}$, and constant current $2400 \mathrm{~mA}$. Soil conductivity in the area of the buried pipelines is $0.005 \mathrm{~S} / \mathrm{m}$. It should be noted that all simulated potential data below are with respect to the saturated copper sulfate reference electrode.

\section{Results and discussion}

\subsection{Effect of pipeline crossing}

Considering the situation of two pipelines intersecting at an angle of $90^{\circ}$, the setting of each parameter is the same as in Sect. 4. Both potential distribution and current density distribution of pipeline 2 are obtained by simulation, and the results are shown in Fig. 7.
As shown in Fig. 7a, the change in the potential distribution of pipeline 2 is very large where the two pipelines intersect. The corrosion potential near the intersection is higher than the self-corrosion potential, and the potential of the intersection is then most positive. The potential at each end of the pipeline is lower than the pipeline self-corrosion potential. Considering the stray corrosion current density in Fig. 7b, in this section, the current density is positive which means that the current flows out of the pipeline. Therefore, that section of the pipeline becomes an anode, and its potential is higher than the self-corrosion potential which makes corrosion more severe. The section that shows a negative current density has current flowing into the pipeline-in other words, it becomes a cathode. Its potential is lower than the self-corrosion potential. It receives some cathodic protection which reduces corrosion.

\subsection{Effect of pipeline crossing on the cathodic protection potential distribution}

The following assumptions are made: Pipeline 2 also receives applied impressed current cathodic protection. The coordinates of the auxiliary anode of pipeline 2 are $(100 \mathrm{~m},-800 \mathrm{~m}$, $-1 \mathrm{~m})$ and $(100 \mathrm{~m},-800 \mathrm{~m},-6 \mathrm{~m})$. The current is also $2400 \mathrm{~mA}$, and the rest of the parameters remain unchanged. The distribution of the cathodic protection potential and current density of two pipelines are shown in Fig. 8.

According to Fig. 8, a large change of the cathodic protection potentials occurs near the intersection between the two pipelines. There is a clear potential increase with the maximum at the intersection. The current density, 

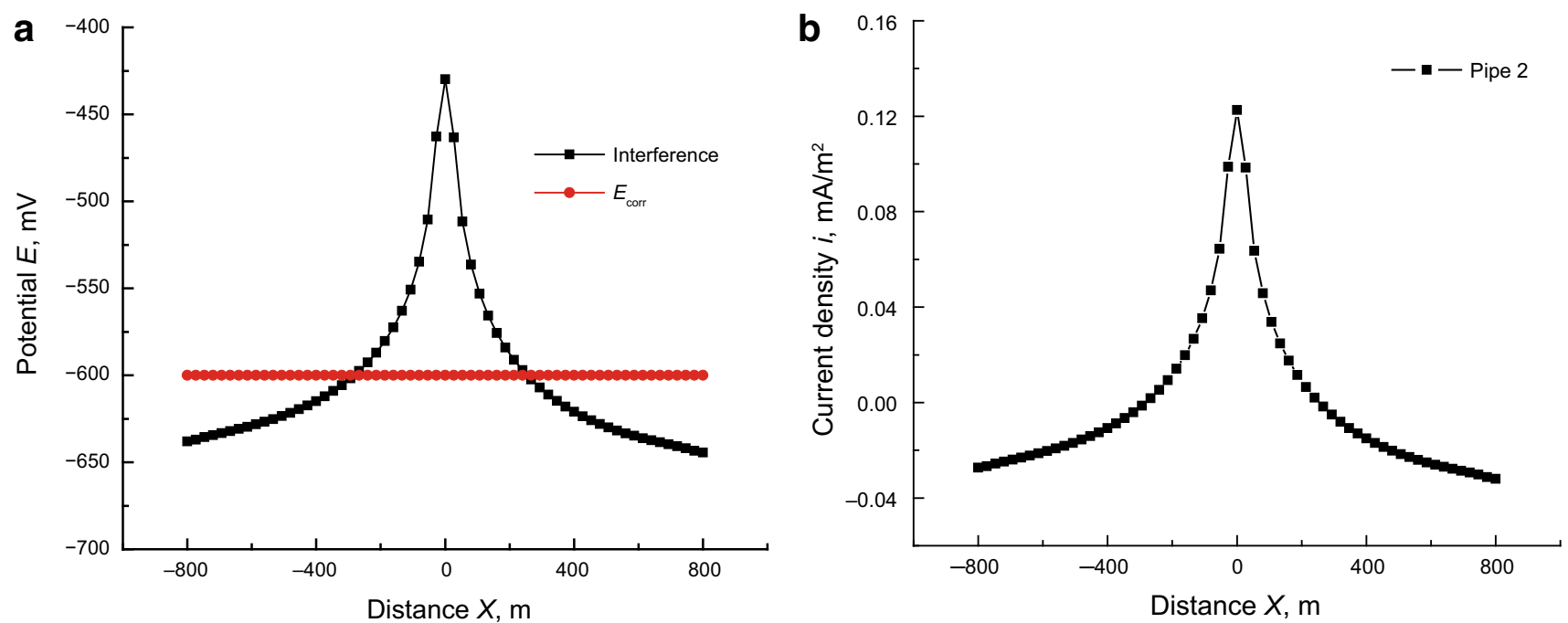

Fig. 7 Calculated effect of pipeline crossing. a Potential distribution. b Stray current density distribution
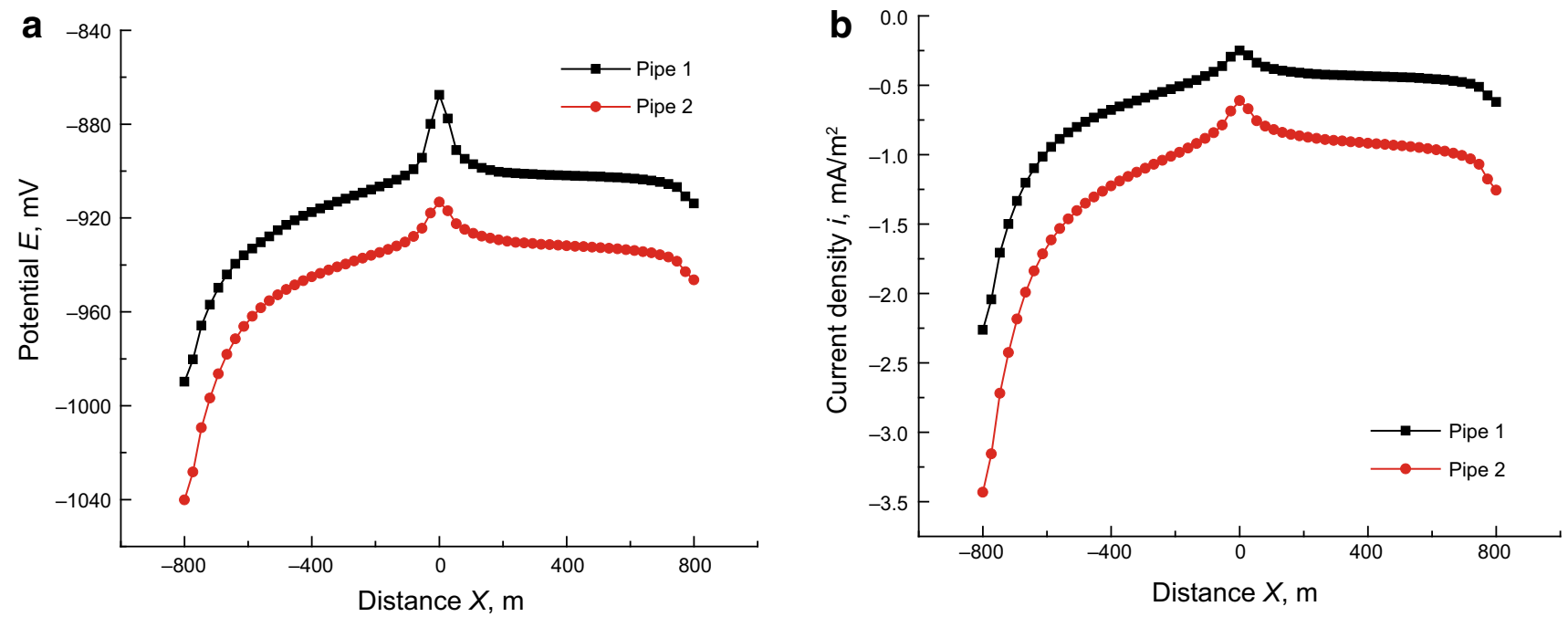

Fig. 8 Calculated effect of pipeline crossing on the cathodic protection potential (a) and calculated current density distribution (b)

however, is low near the intersection and almost zero at the intersection itself. Therefore, the degree of pipeline cathodic protection is weakened around the intersection, possibly causing insufficient protection.

\subsection{Calculated effect of changing the crossing angle}

We simulated both corrosion potential and current density distribution of pipeline 2 for four different crossing angles between the two pipelines: $30^{\circ}, 45^{\circ}, 60^{\circ}$, and $90^{\circ}$. The different angles are obtained by rotating pipeline 2 anticlockwise, while all other parameters remain unchanged. The results are shown in Fig. 9.

Figure 9 reveals that the potential near the intersection becomes increasingly negative on increasing the crossing angle from $30^{\circ}$ to $90^{\circ}$. However, the change of potential within the first $100 \mathrm{~m}$ of the intersection is only about $30 \mathrm{mV}$. On the other hand, the calculated potential change a few hundred meters away from the intersection is relatively large. This is because the relative position between the pipeline and the auxiliary anode has changed more significantly while the location of both anode and intersection remains unchanged. This is very important when comparing the potentials of intersections.

\subsection{Calculated effect of changing the vertical crossing distance}

We simulate the corrosion potential and current density distribution of pipeline 2 buried at depths $0.5,1,2$, and $3 \mathrm{~m}$-see Fig. 10. Other parameters remain unchanged. 

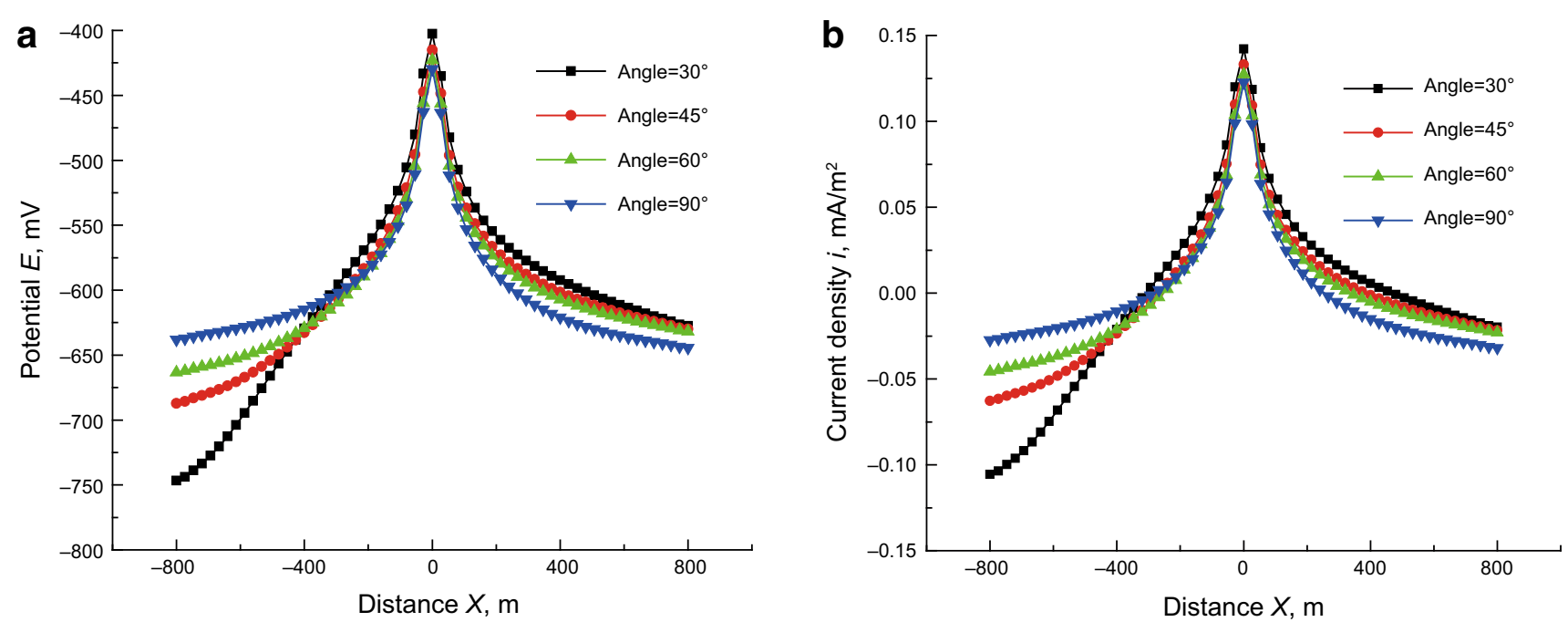

Fig. 9 Calculated effect of different crossing angles. a Potential distribution. b Stray current distribution
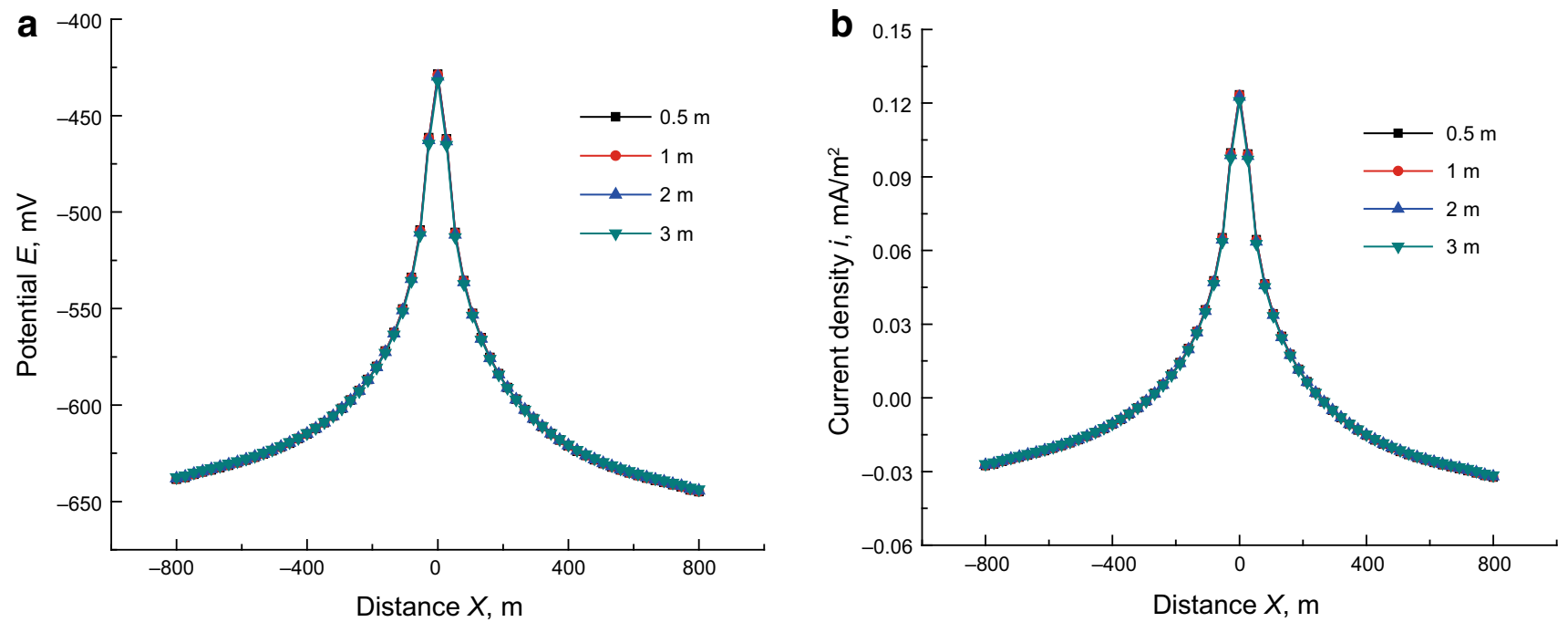

Fig. 10 Calculated effect of changing the vertical crossing distance. a Potential distribution. b Stray current distribution

Our calculated results indicate that both the pipeline corrosion potential and the current density remain practically unchanged for the different vertical crossing distances in the range investigated.

\subsection{Calculated effect of the horizontal distance between parallel pipelines}

The distance between parallel pipelines can vary a lot in practice. We simulate both the potential distribution and the current density distribution of pipeline 2 for distances of $0,50,100,150$, and $200 \mathrm{~m}$ with all other parameters unchanged. The simulated results are shown in Fig. 11.

Our results indicate that the potential distribution of pipeline 2 becomes more negative as the horizontal distance between two pipelines increases. Also the potential distribution of the entire pipeline becomes more evenly distributed. From the distribution of the stray current density, we know that the current density will decrease with increasing distance and that the current density of most types of intersections is about zero within $200 \mathrm{~m}$. Here the DC interference from stray current turns out to be very small. As a result, DC interference in pipeline 2 decreases with increasing horizontal distance.

\subsection{Calculated effect of anode output current}

The anode output current has a strong influence on the magnitude of the stray current. Here we calculate both the potential distribution and the current density distribution of pipeline 2 for three anode output currents: 1500, 2400, and 

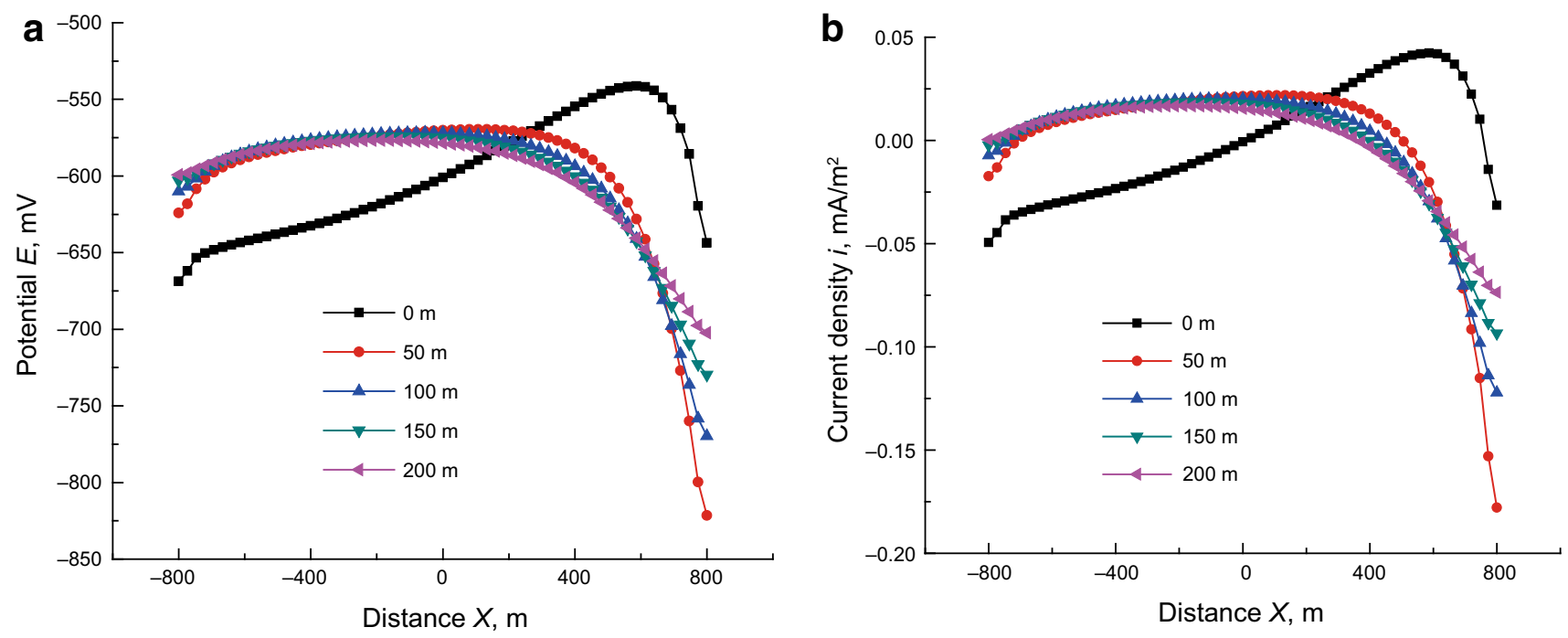

Fig. 11 Calculated effect of changing the horizontal distance between two parallel pipes. a Potential distribution. b Stray current distribution
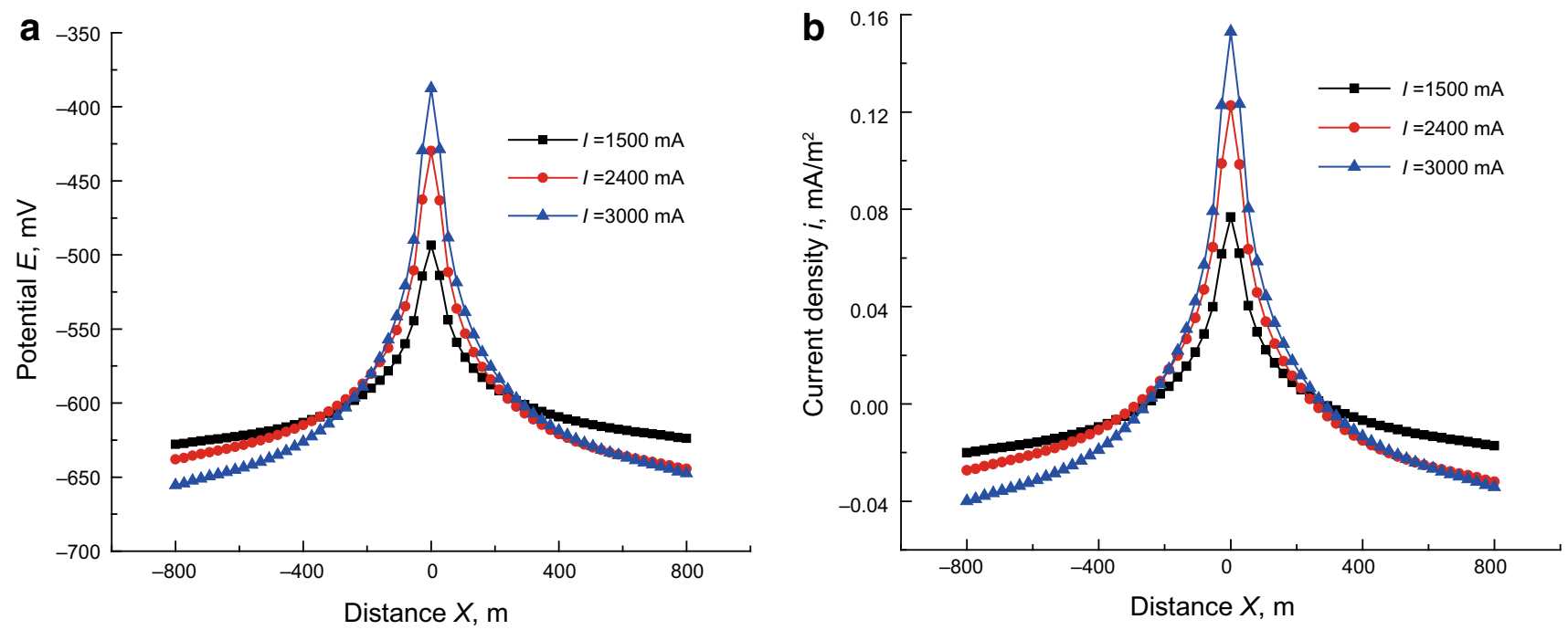

Fig. 12 Calculated effect of the anode output current. a Potential distribution. b Stray current density distribution

$3000 \mathrm{~mA}$. All other parameters remain unchanged. The simulation results are shown in Fig. 12.

Both the corrosion potential distribution and the current density distribution around pipeline 2 change significantly with an increase in the anode output current. When the anode output current increases, a large current flows into the lower end $(-800 \mathrm{~m})$ of pipeline 2 (consistent with Fig. 12b) and the potential decreases gradually. Because a large current flows into the lower end of pipeline 2, a large current will flow out of pipeline 2 from the intersection. The potential will increase and become greater than the self-potential, and the DC interference becomes more severe. Interestingly despite the increase in the anode output current, both the potential distribution and the current density distribution for the upper end $(800 \mathrm{~m})$ of pipeline 2 remain unchanged.

\subsection{Calculated effect of anode depth}

We would expect that the anode depth can strongly affect the DC interference. We simulated the potential distribution and the current density distribution for pipeline 2 for varying anode depths $(3.5,23.5$, and $53.5 \mathrm{~m})$. All other parameters remain unchanged. The results are shown in Fig. 13.

To our surprise, the results indicate that both the pipeline potential distribution and the current density remain 

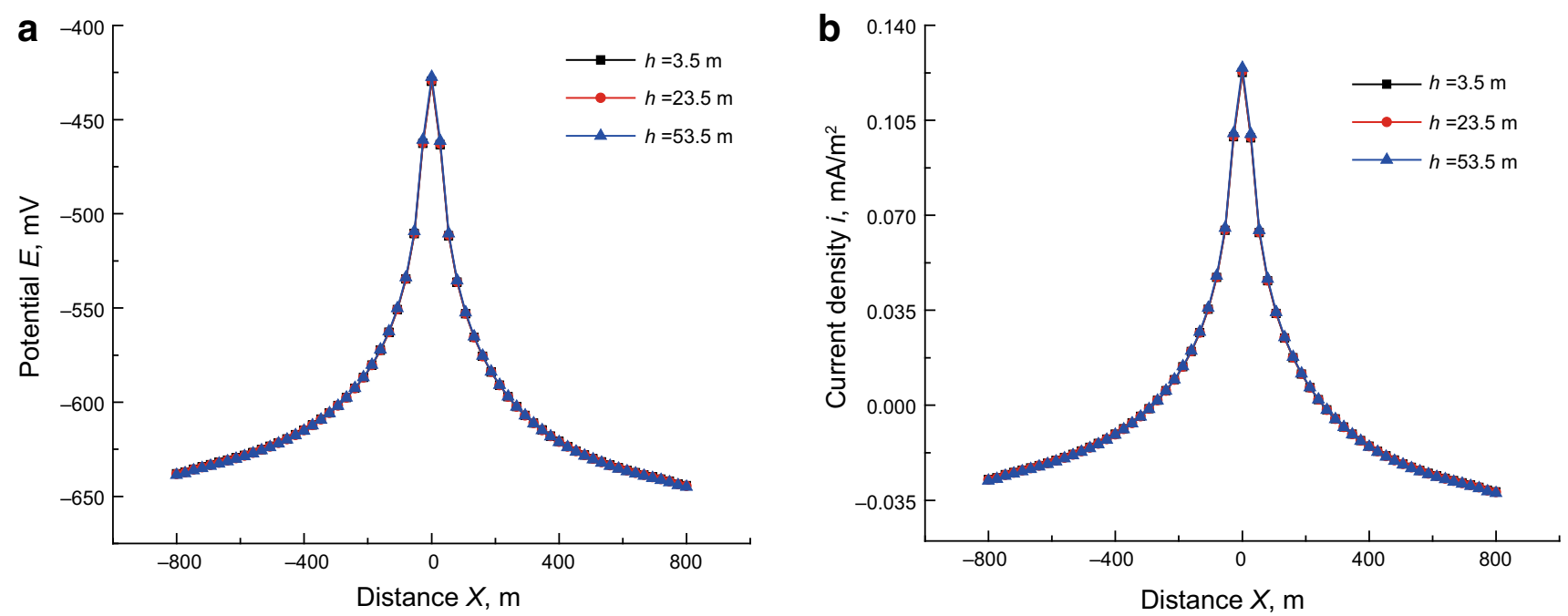

Fig. 13 Calculated effect of changing anode depths. a Potential distribution. b Stray current density distribution
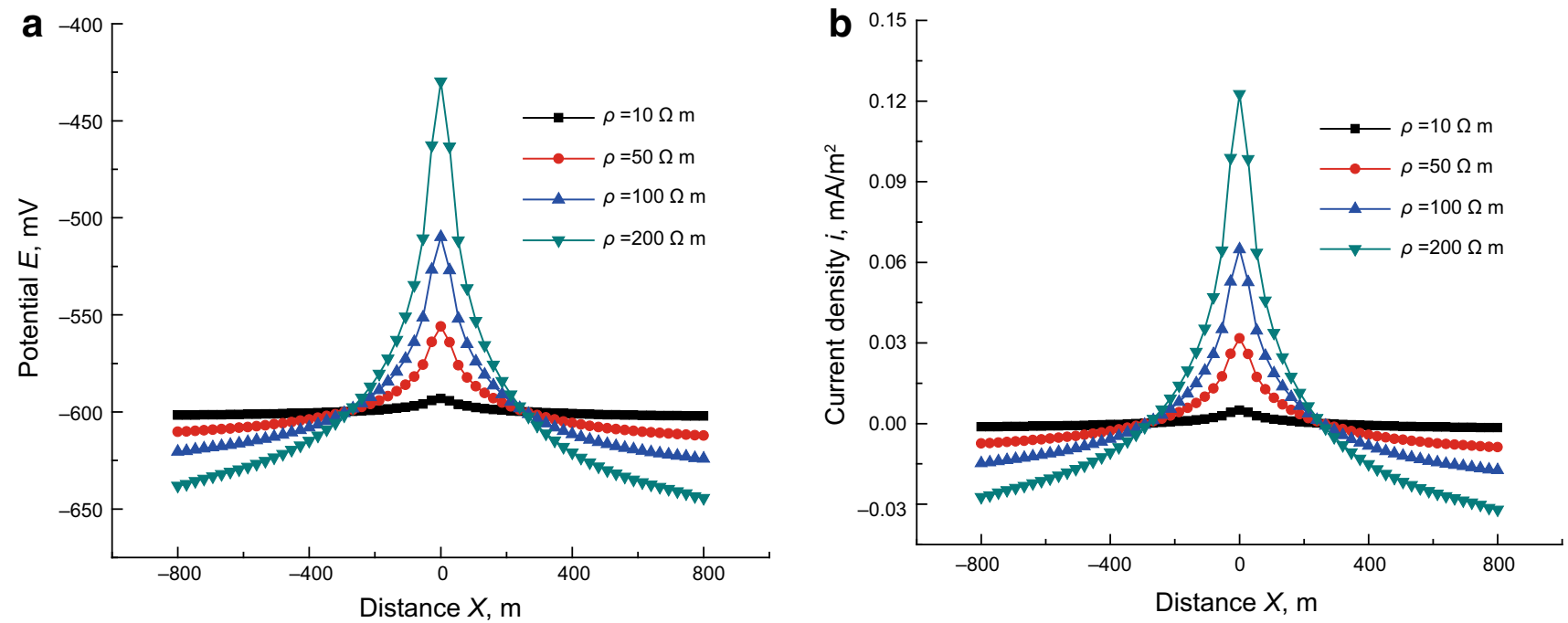

Fig. 14 Calculated effect of soil resistivity. a Potential distribution. b Stray current density distribution

practically unchanged when the anode depth changes, in the range investigated. A possible explanation may be that the distance between the anode and pipeline $2(400 \mathrm{~m})$ is much larger than the considered anode depths. Therefore, at least in our modeled scenario, the anode depth shows no significant impact on the DC interference of pipeline 2.

\subsection{Calculated effect of soil resistivity}

Soil resistivity has a strong influence on the magnitude of the stray current. We simulate both the corrosion potential and the current density distribution for the pipeline with soil resistivities of $10,50,100$, and $200 \Omega \mathrm{m}$. All other parameters remained unchanged. The simulation results are shown in Fig. 14.
Both the potential distribution and the current density distribution of pipeline 2 become very uneven if the soil resistivity is increased. When the soil resistivity is very small, the stray current density of pipeline 2 is near zero and the corrosion potential is approximately the self-corrosion potential. In other words, pipeline 2 is hardly affected. When the soil resistivity is very large, the current density near the pipeline intersection however becomes positive and the corrosion potential is significantly more positive than the self-corrosion potential.

As can be seen in Fig. 14, there are two common intersections between all curves. This means there are two possibilities: The current density between two intersections is positive (current flows out and the associated corrosion 
of the pipeline is more severe) or the current density outside two intersections is negative (current flows in and the pipeline has some cathodic protection).

As a consequence, the change of soil resistivity does not result in the change of the location and length of affected pipe sections. It only affects the degree of corrosion.

\section{Conclusions}

The following conclusions can be drawn based on our experiments and simulation:

(1) The mathematical model of the DC stray current interference in pipelines investigated in this paper is accurate, and BEM is confirmed to simulate DC stray current interference on pipelines very well.

(2) The potential distribution of the pipeline changes a lot when the pipelines cross. The potential at the intersection is about $200 \mathrm{mV}$ higher than the selfcorrosion potential which renders the corrosion of the pipeline in the intersection quite severe. The potentials at the two ends are about $50 \mathrm{mV}$ lower than the self-corrosion potential. This part of the pipeline appears to receive some cathodic protection.

(3) The variation of the pipeline crossing angle, vertical crossing distance, and anode depth has little impact on the potential and the current density distribution of the DC-interfered pipeline.

(4) Upon increasing the horizontal distance between parallel pipelines, the corrosion potential of the affected section becomes negative, the potential distribution becomes more uniform, and the degree of the DC interference decreases.

(5) Upon increasing either the anode output current or the soil resistivity, the corrosion potential of the DCinterfered pipeline becomes very uneven. The corrosion potential of the pipeline near the intersection has a large positive offset, and pipeline corrosion becomes worse. However, the corrosion potential and the current density distribution at the far end $(800 \mathrm{~m})$ of pipeline 2 remain unchanged after increasing the anode output current. Change in resistivity just changes the degree of corrosion of the affected section but does not change the location and length of the affected pipe sections.

Open Access This article is distributed under the terms of the Creative Commons Attribution 4.0 International License (http://creative commons.org/licenses/by/4.0/), which permits unrestricted use, distribution, and reproduction in any medium, provided you give appropriate credit to the original author(s) and the source, provide a link to the Creative Commons license, and indicate if changes were made.

\section{References}

Abootalebi O, Kermanpur A, Shishesaz MR, et al. Optimizing the electrode position in sacrificial anode cathodic protection systems using boundary element method. Corros Sci. 2010;52(3):678-87. doi:10.1016/j.corsci.2009.10.025.

BEASY software user guide, computational mechanics BEASY Version 10. Southampton, UK, 2005. Available: http://www. beasy.com.

Bertolini L, Carsana M, Pedeferri P. Corrosion behavior of steel in concrete in the presence of stray current. Corros Sci. 2007;49(3):1056-68. doi:10.1016/j.corsci.2006.05.048.

Bordón JDR, Aznárez JJ, Maeso O. A 2D BEM-FEM approach for time harmonic fluid-structure interaction analysis of thin elastic bodies. Eng Anal Bound Elem. 2014;43(6):19-29. doi:10.1016/j. enganabound.2014.03.004.

Bortels L, Dorochenko A, Bossche BV, et al. Three-dimensional boundary element method and finite element method simulations applied to stray current interference problems. A unique coupling mechanism that takes the best of both methods. Corrosion. 2007;63(6):561-76. doi:10.5006/1.3278407.

Boumaiza D, Aour B. On the efficiency of the iterative coupling FEM-BEM for solving the elasto-plastic problems. Eng Struct. 2014;72(8):12-25. doi:10.1016/j.engstruct.2014.03.036.

Brichau F, Deconinck J. A numerical model for cathodic protection of buried pipes. Corrosion. 1994;50(1):39-49. doi:10.5006/1. 3293492.

Brichau F, Deconinck J, Driesens T. Modeling of underground cathodic protection stray currents. Corrosion. 1996;52(6):480-8. doi:10.5006/1.3292137.

DeGiorgi VG, Wimmer SA. Geometric details and modeling accuracy requirements for shipboard impressed current cathodic protection system modeling. Eng Anal Boundary Elem. 2005;29(1): 15-28. doi:10.1016/j.enganabound.2004.09.006.

Ding HT, Li LJ, Jiang MH, et al. Lab research of DC \& AC stray current for the failure effect of the gas pipelines buried underground. Guizhou Chem Ind. 2010;35(5):9-12 (in Chinese).

Gao B, Shen LS, Meng XQ, et al. DC stray current corrosion and protection of oil gas pipelines. Pipeline Technol Equip. 2010;4:42-3 (in Chinese).

Guo YB, Liu C, Wang DG, Liu SH. Effects of alternating current interference on corrosion of X60 pipeline steel. Pet Sci. 2015;12(2):316-24. doi:10.1007/s12182-015-0022-0.

Jia JX, Song G, Atrens A, et al. Evaluation of the BEASY program using linear and piecewise linear approaches for the boundary conditions. Mater Corros. 2004;55(11):845-52. doi:10.1002/ maco.200403795.

Lacerda LAD, Silva JMD, Jose L. Dual boundary element formulation for half-space cathodic protection analysis. Eng Anal Bound Elem. 2007;31(6):559-67. doi:10.1016/j.enganabound.2006.10. 007.

Lan ZG, Wang XT, Hou BR, et al. Simulation of sacrificial anode protection for steel platform using boundary element method. Eng Anal Boundary Elem. 2012;36(5):903-6. doi:10.1016/j. enganabound.2011.07.018.

Li YT, Wu MT, Zheng F, et al. Stray current monitoring for pipelines and an application example in the Chuanxi gas field. Total Corros Control. 2010;24(1):25-8 (in Chinese).

Li ZL, Cui G, Shang XB, et al. Defining cathodic protection potential distribution of long distance pipelines with numerical simulation. Corros Prot. 2013;34(6):468-71 (in Chinese).

Liang CH, Yuan CJ, Huang NB. Defining the voltage distribution of a pipeline in frozen earth under cathodic protection with a boundary element method. J Dalian Marit Univ. 2011;37(4): 109-16 (in Chinese). 
Liu C, Shankar A, Orazem ME, et al. Numerical simulations for cathodic protection of pipelines. Undergr Pipeline Corros. 2014;63:85-126.

Liu GC, Sun W, Wang L, et al. Modeling cathodic shielding of sacrificial anode cathodic protection systems in sea water. Mater Corros. 2013;63(6):472-7. doi:10.1002/maco.201206726.

Meng XJ, Wu ZY, Liang XW, et al. Improvement of algorithms for a regional cathodic protection model. J Chin Soc Corros Prot. 1998;9:221-6 (in Chinese).

Metwally IA, Al-Mandhari HM, Gastli A, et al. Factors affecting cathodic-protection interference. Eng Anal Bound Elem. 2007;31(6):485-93. doi:10.1016/j.enganabound.2006.11.003.

Metwally IA, Al-Mandhari HM, Gastli A, et al. Stray currents of ESP well casings. Eng Anal Bound Elem. 2008;32(1):32-40. doi:10. 1016/j.enganabound.2007.06.003.

Parvanova SL, Dineva PS, Manolis GD, et al. Dynamic response of a solid with multiple inclusions under anti-plane strain conditions by the BEM. Comput Struct. 2014;139(7):65-83. doi:10.1016/j. compstruc.2014.04.002.

Poljak D, Sesnic S, Goic R. Analytical versus boundary element modelling of horizontal ground electrode. Eng Anal Bound Elem. 2010;34(4):307-14. doi:10.1016/j.enganabound.2009.10. 008 .
Thamita SK. Modeling and simulation of galvanic corrosion pit as a moving boundary problem. Comput Mater Sci. 2012; 65(12):269-75. doi:10.1016/j.commatsci.2012.07.029.

Wang Y, Yan YG, Dong CF, et al. Effect of stray current on corrosion of Q235, 16Mn and X70 steels with damaged coating. Corros Sci Prot Technol. 2010;22(2):117-9 (in Chinese).

Wrobel LC, Miltiadou P. Genetic algorithms for inverse cathodic protection problems. Eng Anal Bound Elem. 2004;28(3):267-77. doi:10.1016/S0955-7997(03)00057-2.

Wu HT. The application of boundary element method in heat transfer. Beijing: National Defence Industry Press; 2008. p. 24-7 (in Chinese).

Wu JH, Xing SH, Liang CH, et al. The influence of electrode position and output current on the corrosion related electro-magnetic field of ship. Adv Eng Softw. 2011;42(10):902-9. doi:10.1016/j. advengsoft.2011.06.007.

$\mathrm{Xu}$ LY, Cheng YF. Development of a finite element model for simulation and prediction of mechanoelectrochemical effect of pipeline corrosion. Corros Sci. 2013;73(8):150-60. doi:10.1016/ j.corsci.2013.04.004. 